\title{
GÜNLÜK AKARSU AKIMLARININ KAOTİK ANALİZİNDE DALGACIK YAKLAŞIMININ UYGULAMASI
}

\author{
Aslıhan ALBOSTAN ${ }^{1}$, Bihrat ÖNÖZ ${ }^{2}$ \\ İstanbul Teknik Üniversitesi Enerji Enstitüsü Yenilenebilir Enerji Anabilimdalı Maslak / İstanbul 34469 \\ $1_{\text {aalbostan@gmail.com, }}{ }^{2}$ onoz@itu.edu.tr
}

(Geliş/Received: 24.12.2013; Kabul/Accepted: 13.11.2014)

\begin{abstract}
ÖZET
$\mathrm{Su}$; sağlıklı ve kaliteli bir yaşamın vazgeçilmez unsurudur. Bu sebeple su kaynaklarının verimli kullanımı büyük önem arz etmektedir. Su havzaları; içme suyu, sulama, enerji üretimi başta olmak üzere birçok amaca hizmet vermektedir Etkisi her geçen gün daha fazla hissedilen iklim değişimi göz önünde bulundurulursa, kaynakların verimli kullanımı için, doğru ve etkin işletme politikalarına ihtiyaç duyulmaktadır. Kaynakların verimli kullanımını sağlamak için; kaynaktan elde edilen verilerin iyi analiz edilmesini, yüksek başarım ile öngörülmesi ve bu başarımı sağlayacak yeni yöntemlerin geliştirilmesine ihtiyaç duyulmaktadır. Bu bağlamda; bu çalışmada kaotik analizin günlük akım verilerine uygulanarak sistemin öngörülebilirliği ve öngörü başarısı üzerinde durulmuștur. Çalıșmada Coruh Havzası'nda gözlenmiș 33 yıllık günlük akım verileri kullanılmıștır. Serinin gözlem süresinin, sistemin karakterinin belirlenebilmesi için yeterli uzunlukta olduğu kabul edilmiştir. Ayrıştırma yapılırken, sistemin taşıdığı bilginin bir ölçütü olan entropi kavramı, uygun seviyenin seçilmesi için kriter olarak dikkate alınmıștır. Çalıșmanın sonuçlarında, Çoruh Havzası verilerinin kaotik karaktere sahip olduğu, kaotik analiz kapsamında kullanılan, lokal öngörü yöntemi ile akım verilerinin başarılı bir șekilde öngörülebildiği görülmüş̧ür. Ayrıca dalgacık analizi neticesinde elde edilen yaklaşıklık parçasının, veri kümesinin orijinal haline göre daha yüksek öngörü performansı gösterdiği sonucuna varılmıştır.
\end{abstract}

Anahtar Kelimeler: Kaotik analiz, dalgacık analizi, günlük akım serileri, öngörü

\section{WAVELET APPLICATION APPROACH ON THE CHAOTIC ANALYSIS OF DAILY RIVER DISCHARGE}

\begin{abstract}
Water is an indispensable requirement for health and quality of life. For this reason, the efficient use of water resources play a significant role. Water basins serve many purposes such as drinking water supply, irrigation and energy production. Considering all those purposes, accurate and effective management policies are needed for the efficiency of water resource usage. In particularly, the gauged data need good analysis, and accurate predictability. Beside, implementation of new developed methods is highly important to enhance the performance of predictability. This study is an implementation of chaotic analysis on hydrological series to determine the predictability of the system and observe the prediction performance. The daily discharge data of Coruh basin with 33-years record was used. The length of the data is considered to be long enough for determining the system characteristics. In addition, wavelet approach is used to decompose data its component to ensure a more detailed analysis. The entropy concept which is a measure of the information carried by the system is taken into account to determine the appropriate level of decomposition. In the results, it is observed that the data of Çoruh river basin, is performed a chaotic character and responds with a good performance to the prediction method of local approximation under chaotic analysis. Beside all, the approximation component of wavelet decomposition exhibits a better performance to the original data set in local approximation prediction.
\end{abstract}

Keywords: Chaotic analysis, wavelet analysis, daily flow series, forecasting

\section{GİRIŞ (INTRODUCTION)}

Sistem teorisine göre, sistem; mantıksal bir bütünlüğü ve tutarlığ 1 olan fikir ve prensipler topluluğu, karşılıklı ilişki ve etkileşim içerisinde bulunan parçaların meydana getirdiği bir bütün veya belirli kurallara göre işleyen bir mekanizma olarak tanımlanmıştır. Sistemler birçok alt grupta incelenebilmektedir. Kendiliğinden doğada var olan sistemlere, "doğal sistemler" denir [1, 2]. Doğal 
sistemler, insan yapısı sistemlere göre daha karmaşık ve analizi zor sistemlerdir.

Çevredeki değişimlere tepkisi bakımından ise sistemler, dinamik ve statik sistemler olmak üzere iki grupta incelenebilirler. Doğal sistemler, değişikliklere uğrayan sistemler olduğundan çoğunlukla dinamik sistem sinıfinda incelenirler. Dinamik sistemler, kararlı ve kararlı olmayan davranışlar gösterebilmektedir, sistem davranışlarının belirlenmesi için doğrusal ve doğrusal olmayan yöntemler kullanılmaktadır. Doğrusal olmayan yöntemler içerisinde, düzensizliğin ifadesi olarak kabul edilebilen kaotik davranışın, en belirgin özelliği başlangıç şartlarına olan hassas bağımlılıktır. $\mathrm{Bu}$ nedenle, kaotik sistemlerde, sistemin zaman içindeki gelişimini belirleyebilmek için başlangıç şartlarını sonsuz hassasiyetle bilmek gerekmektedir. Doğal sistemlerin bir parçası olan su havzaları, birçok amaç için kullanılmaktadır. Bu amaçlardan; içme suyu temini, sulama ve enerji üretimi, günümüzde önemli bir hedef olarak görülen sürdürülebilir kalkınmanın sağlanabilmesi açısından son derece önemlidir. Bu amaçların etkin olarak yerine getirilebilmesi için, havza özelliklerinin analiz edilmesi gerekmektedir. Akarsu havzalarının etkin ve doğru bir şekilde modellenebilmesi için akımı oluşturan süreçler hakkında ayrıntılı ve yeterli bilgiye sahip olmak gerekmektedir. Akarsu havzaları verilerinden, günlük veriler özellikle enerji üretimi başta olmak üzere, içme suyu ve sulama amaçları için en çok kullanılan veri kümesidir $\mathrm{Bu}$ sebeple, akım gözlem istasyonlarına ait verilerden günlük periyotta örneklenen verilerinin havza analizinde kullanımı çok yaygındır. Kantz ve Schrieber zaman serilerinin stokastik ve deterministik parçalardan oluşan sistemler olduğunu belirtmişlerdir. Stokastik özellik gösteren bir sistemin bile içerisinde deterministik bileşen ihtiva ettiğini öne sürmüşlerdir. [3]. Sistemin bileşenlerinin detaylı değerlendirilmesi birçok bilim dalının ilgi alanına girmektedir. Nitekim, aynı konu hidroloji alanında çalışan araştırmacıların da ilgisini çekmiş ve 1989 yılında Rodriguez- Iturbe [4], yağıŞ verilerinin çok boyutlu bir uzayda, bir çeker ile ifade edilebilirliği üzerine bir araştırma yapmışlardır. Kaos teorisi kapsamında geliştirilen yöntemleri, inceledikleri yağış verisi sitemine uygulamış ve sistemin faz uzayında çekeri oluşturarak, sistemin dinamiğini ortaya koymuşlardır. Jayawerdana ve Lai [5], bu yaklaşımı göz önünde bulundurarak yaptıkları çalışmada; günlük yağış miktarı verileri kullanarak faz uzayını yeniden kurmuşlar ve lokal öngörü yöntemini kullanarak başarılı sonuçlar elde etmişlerdir. Porporato ve Ridolfi [6], Grassberger ve Proccocacia [7] tarafından geliştirilen kaotik analiz yöntemini kullanarak, basit gürültü giderimi yöntemi ile sistemin çok boyutlu faz uzayındaki çekerini elde etmiş, ve sistemin gerek orijinal gerekse faz uzayı kullanılarak yapılan öngörüde, daha başarılı sonuçlar verdiğini ortaya koymuşlardır [7]. Günlük akım verileri üzerinde yapılan kaotik ilk çalışma, Birleşik Devletler'deki Reynolds dağlarının kar erimesi üzerinde yapılmıştır. Yapılan araştırmada, korelasyon boyutları yöntemi ile yeniden kurulan faz uzayında oluşan çekicide beklenen düşük dereceli fraktal (tam sayı olmayan) boyuta rastlanmamış ve bölgedeki kar erimelerinin rastgele hareketinin fiziksel veya iklimsel ilişkiler ile ilgili olduğu ve deterministik bir hareket olmadığ 1 sonucuna varılmıştır [8]. Fakat, 1994 yılında yapılan başka bir çalışmada, Hong Kong'daki günlük nehir akım verileri analiz edilmiş, kaotik karakter belirlenmiş ve öngörü yapılmıştır. Bu çalıșma nehir akımları üzerinde lokal öngörü yöntemi ile kaotik analiz neticesinde yersel yaklaşım yöntemi ile öngörü yapılan ilk çalışmadır [4]. Bugüne kadar yapılan çalışmalarda, hidrolojik veriler gibi doğal sistemlere ait verilerin gürültü içeriği sürekli vurgulanmış ve kaotik analiz yapılırken, sistemin gürültüsünün giderilmesinin önemine değinilmiştir [9]. $\mathrm{Bu}$ çalışmada, kaotik analizin hidrolojik verilere uygulanmasında, sistemin faz uzayı yeniden kurularak öngörü başarımının gözlenmesi amaçlanmıştır. Çoruh havzasında, 33 yıllık, günlük periyotlara süresi ile kayıt altına alınan veriler kullanılmıştır. Serinin kayıt süresi, sistemin karakterinin belirlenebilmesi için yeterli uzunlukta kabul edilmiştir. Ayrıca bu çalışmada, hidroloji alanında yapılan diğer çalışmalara ek olarak, veri kümesi, dalgacık analizi kullanarak bileşenlerine ayrılmıştır. Ayrıştırma işlemi yapılırken, sistemin taşıdığı bilginin bir ölçütü olan entropi kavramı kullanılmıştır. Çalışmanın sonuçlarında, dalgacık analizi neticesinde elde edilen yaklaşıklık parçasının, veri kümesinin orijinal haline göre daha yüksek bir öngörü performans gösterdiği sonucuna varılmıştır. Ülkemizde, enerji üretiminde büyük paya sahip hidroelektrik santrallerin planlanması ve işletilmesi açısından günlük periyot ile kayıt altına alınan verilerin iyi analiz edilmesinin yanı sıra, yüksek başarım ile öngörülmesi ve bu başarımı sağlayacak yeni yöntemlerin geliştirilmesi ihtiyaç haline geldiği göz önünde bulundurulursa, bu çalışma bu ihtiyaca yönelik örnek bir çalışma niteliği taşımaktadır.

\section{YÖNTEM (METHODOLOGY)}

Dinamik sistemler teorisine göre, bir sistemin zamansal evrimi faz uzayındaki yörüngeleri ile temsil edilebilir. Faz uzayının koordinatları, sistemin evrimini tam olarak gösterebilmek için gerekli olan durum değişkenlerinden meydana gelir [10].

\subsection{Faz Uzayının Yeniden Kurulması (Phase Space Reconstruction)}

$x(n)=x\left(t_{0}+n \tau s\right)$ ile ifade edilen bir zaman serisinden, sistemin faz uzayının yeniden kurulumunda, zaman gecikmeli koordinatlar yöntemi, kullanılabilir. Zaman gecikmeli koordinatlar yöntemi, dinamik bir sisteme ait skaler veriden çok boyutlu faz uzayına geçiş için kullanılan bir yöntemdir [11]. Yönteme göre, eğer zaman boyunca bir sistemde yalnızca tek bir değişken izleniyorsa, orijinal verinin zaman gecikmeli kopyaları kullanılarak, bu değişkenden sistemin 
mevcut dinamiklerini hesaplamak mümkündür [11]. Zaman serisini oluşturan dinamik sistemin çekeri, Takens [12] teoremi ile verinin zaman gecikmeli kopyaları kullanılarak $m$ boyutlu faz uzayında oluşturulur (Eşitlik 1).

$y i=(x(i \Delta t), x(i \Delta t+T), x(i \Delta t+2 T)$,

$x(i \Delta t+\ldots \ldots \ldots \ldots(m-1) T))$

Bu eşitlikte, $T$ zaman gecikmesi, $m$ gömülü boyuttur. Faz uzayında oluşan bu özgün paterne çeker adı ve verilir.

\subsubsection{Zaman Gecikmesinin Belirlenmesi (Estimating the Time Delay)}

Zaman gecikmesine yönelik daha ileri bir yaklaşım, ortak bilgi fonksiyonlarının (OBF) incelenmesidir. Fraser ve Swinney [14], birbirlerine komşu olan veri noktalarının, $x\left(t_{j}\right), x\left(t_{j}+T\right)$, istatistiksel olarak bağlı olup olmadıklarının bir ölçüsü olarak ortak bilgi fonksiyonunu önermişlerdir. OBF, otokorelasyon ilişkisinin doğrusal olmayan bir açılımı olarak düşünülebilir. Eğer $\mathrm{P}(\mathrm{x}(\mathrm{n}))$ ve $\mathrm{P}(\mathrm{x}(\mathrm{n}+\mathrm{T}))$ ardişık koordinatların iki ayrı olasılık dağılımı ise, ve $\mathrm{P}(\mathrm{x}(\mathrm{n})$, $\mathrm{x}(\mathrm{n}+\mathrm{T}))$ ) olasılık dağılımı zaman gecikmesinin bir fonksiyonu olarak aşağıda verilen eşitlik ile hesaplanabilir.

$$
O B(T)=\sum_{t} \mathrm{P}(\mathrm{x}(\mathrm{n}), \mathrm{x}(\mathrm{n}+\mathrm{T})) \log \left(\frac{\mathrm{P}(\mathrm{x}(\mathrm{n}), \mathrm{x}(\mathrm{n}+\mathrm{T}))}{(\mathrm{P}(\mathrm{x}(n)), \mathrm{P}(\mathrm{x}(n+T))}\right)
$$

$\mathrm{Bu}$ ifade fiziksel sistemden alınan ölçümlere uygulanırsa; ölçüm değerleri x(n), A kümesi olarak, T kadar bir zaman gecikmesi sonra alınan ölçümler de, $\mathrm{x}(\mathrm{n}+\mathrm{T}), \quad \mathrm{B}$ kümesi olarak düşünülebilir. $\mathrm{T}$ ve $(\mathrm{n}+\mathrm{T})$ 'deki ölçümler arasındaki ortalama karşılıklı bilgi (I), Eşitlik 3 kullanılarak bulunur [13].

$$
\begin{aligned}
& I_{A B}(T)=\sum_{a_{i} b_{k}} P_{x(n), x(n+T)}(x(n), x(n+ \\
& \cdots T)) \log _{2}\left\lceil\frac{P_{x(n), x(n+T)} x(n), x(n+T)}{P(x(n)) P(x(n+T))}\right\rceil, I(T) \geq 0
\end{aligned}
$$

Faz uzayının kurulabilmesi için gerekli optimum $\mathrm{I}(\mathrm{t})$ 'nin seçimi önemlidir. Eğer T çok küçükse $\mathrm{x}(\mathrm{n})$ ve $\mathrm{x}(\mathrm{n}+\mathrm{T})$ ölçümleri birbirleri hakkında çok fazla bir şey söyleyemez ve her iki ölçümün de yapılmasına gerek yoktur. Eğer $\mathrm{T}$ çok büyükse I(T) sıfıra yaklaşır ve $\mathrm{x}(\mathrm{n})$ ile $\mathrm{x}(\mathrm{n}+\mathrm{T})$ arasında zamansal ilişki çok zayıftır. Zaman gecikmesi T, I(T)'nin ilk minimum olduğu yer dikkate alınmalıdır. Çünkü; bu durumda ölçümler istatistik olarak bağımlı olabilmekle birlikte zamansal olarak zayıf olduğu söylenebilir [14].

\subsection{Gömme Boyutunun Belirlenmesi (Estimating the Embedding Dimension)}

Öklit uzayında boyut; verilen bir noktanın konumunun tam olarak belirlenmesi için gereken minimum koordinat sayısıdır. Dinamik bir sistemin boyutu ise, sistem dinamiğini tanımlamak için gerekli durum değişkeni sayısıdır. Tanımlanan boyutlar, faz uzayında oluşturulmuş çekiciyi tanımlayamazlar. Faz uzayındaki çekicilerin boyutu tam sayı değil, fraktal yapıdadır [15]. İncelen zaman serisiyle sürekli bir sistemin arasındaki bağlantı, zaman serisinin kendisinden elde edilen doğru gecikme parametreleri ile detaylı bir süreç sonunda elde edilir. Uygulamada sürekli bir zaman serisi elde edilemeyeceğinden, zaman serisinde iki ardışık ölçüm arasında geçen süre $\mathrm{t}_{\mathrm{i}}=\mathrm{t}_{0} \tau_{\text {örn }}$ ile ilişkilidir. Bu eşitlikte $\tau_{\text {örn }}$, örnekleme zamanını ifade etmektedir. Eğer $t_{0}=0$ varsayılırsa, $\mathrm{t}_{\mathrm{i}}=\mathrm{i} \tau_{\text {örn }}$ olarak yazılabilir. Eğer $\mathrm{k} \in \mathrm{Z}^{+}$belirli bir gecikme aralığ $1(\tau) ; \tau=v \tau_{s}$, olduğu varsayılırsa $\mathrm{t}_{\mathrm{i}}+\mathrm{k} \tau=(i+k v) \tau_{s}$ şeklinde ifade edilebilmektedir. Faz uzayının yeniden kurulumu sürecinde amaç, vektörleri oluşturan doğru $\tau$ ve doğru gömme boyutunu (m) ile iki boyutlu gecikmeli koordinatlar metodu ile yeniden kurulumu tamamlamaktır [13]. Gömme uzayında çekici yörüngesini tasvir edecek vektörler zaman gecikmeli koordinatlar metodu süreci ile üretildikten sonra, bu vektörler üzerinden korelasyon boyutu hesaplanabilir. Bu çalışmada, faz uzayı ile oluşan sistemin boyutunun belirlenmesi için, korelasyon boyutu yöntemi kullanılmıştır.

\subsubsection{Korelasyon Boyutu (Correlation Dimension)}

Gömme uzayında çekici yörüngesini tasvir edecek vektörler zaman gecikmeli koordinatlar metodu süreci ile üretildikten sonra, bu vektörler üzerinden korelasyon boyutu hesaplanabilir.

$C^{m}(\varepsilon)=\frac{1}{N(N-1)} \sum_{i, j=1, i \neq j}^{N} \Theta\left(\varepsilon-\left\|s_{i}-s_{j}\right\|\right.$

Eşitlik (4)'te gömme değerinde (m)'leri denemek suretiyle, farklı gömme boyutları için grafik çizildiğinde belirli bir boyutta grafik doyuma ulaşır. $\mathrm{Bu}$ doyum noktasına karşılık gelen $\mathrm{m}$ değeri uygun gömme boyutu olarak seçilebilir. Verinin faz uzayında yeniden oluşturulmasında amaç, yeteri kadar büyük bir Öklid uzayı $\left(\mathrm{R}^{\mathrm{m}}\right)$ sağlayarak, sisteme ait çekici yapısını herhangi bir belirsizlik olmadan görebilmektir. Böylece $\mathrm{m}$ boyutunda birbirine çok yakın olan iki nokta, m'nin daha büyük değerlerine sahip bir uzay içinde görünür hale gelir [12]. Eğer çekici bir boyutlu ise ve iki boyutlu uzayda çizdirilmişse, çekici kendi üzerine katlanır yani ayırım noktalarında kendini kesen bir boyutlu çizgidir [14]. $\mathrm{Bu}$ ayırım noktalarında bir belirsizlik vardır çünkü noktaların komşu olduğu diğer noktaların hangileri olduğu belirlenemez. Bu belirsizlik, çekicinin üç boyutlu uzay içinde çizdirilmesiyle çözülür. Bu durumda kesişim noktaları görünür hale gelir. Bütün belirsizliklerin çözüldüğü $\mathrm{R}^{\mathrm{m}}$ uzayı, çekici gömme boyutunu verir. Eğer verinin gerektirdiğinden çok daha büyük boyutlarda çalışılırsa, veriden istenilen özelliklerin çıkartılması için yapılan hesaplamaların sayısı artar ve gereksiz zaman harcanır. Gömme boyutunun belirlenmesi için literatürde bir çok 
yöntem bulunmakla birlikte, yanlış en yakın komşular yöntemi en çok kullanılan metottur. Yanlış en yakın komşular metodu (YEK), Kennel vd. [15] tarafindan sunulan ve sıkça kullanılan bir metottur (Eşitlik (5)).

$$
a(i, m)=\frac{\left\|y_{i}(m+1)-y_{n(i, m)}(m+1)\right\|}{\left\|y_{i}(m)-y_{n(i, m)}(m)\right\|}, i=1,2,3 \ldots N-m T
$$

Algoritmanın genel içeriğinde, m-boyutlu bir uzayda, seçilen $\vec{\varepsilon}_{i}$ noktasına en yakın $\vec{\varepsilon}_{j}$ komşu noktası aranır. Bu noktalar arasındaki, $\left\|\vec{\varepsilon}_{i}-\vec{\varepsilon}_{j}\right\|$, her iki nokta için tekrarlanarak Eşitlik (6)'deki R mesafesi hesaplanır.

$$
R_{i}=\frac{\left|\varepsilon_{i+1}-\varepsilon_{j+1}\right|}{\left\|\bar{\varepsilon}_{i}-\bar{\varepsilon}_{j}\right\|}
$$

\subsection{Gürültünün Azaltılması (Noise Reduction)}

Doğal veri genellikle gürültü içermektedir. Eğer verinin kaynağ 1 doğrusal bir sistem ise deneysel verinin frekans spektrumu belirgin spektral tepelere sahiptir ve istenen bilgi arka plandaki istenmeyen gürültüden kolaylıkla ayrılabilir. Bunun için bilgi taşıyan parça ile gürültü arasındaki farklara bakılmalıdır ve eğer sinyal ile gürültü frekans spektrumunda farklı bantlarda ise bu Fourier analizi ile tespit edilebilir. Verinin kaynağı kaotikse, bilgi de arka plandaki sinyal de geniş bantlıdır ve Fourier analizi bu ayırımı yapmak için yeterli değildir [16]. Dalgacık dönüşümü; Fourier dönüşümünden farklı olarak düşük frekanslar için geniş, yüksek frekanslar için dar olacak şekilde değişen pencere boyutlarına sahiptir. Dalgacık dönüşümü farklı frekanslarda durağan olmayan güce sahip zaman serisi analizinde kullanılabilir. Dalgacık dönüşümü bir ana fonksiyonun (dalgacık) ötelenme ve yayılması ile oluşturulan baz fonksiyonlarına, işaretin izdüşümünün alınması ile bulunur [17]. Böylelikle, sinyalin yüksek ve düşük frekanslı bileşenleri, zaman bilgisi ile birlikte elde edilebilir. Dalgacık dönüşümü Eşitlik (79) ile ifade edilir;

$$
\begin{aligned}
& \mathrm{W}(\mathrm{a}, \mathrm{b})=\frac{1}{\sqrt{\mathrm{a}}} \int_{-\infty}^{\infty} \mathrm{x}(\mathrm{t}) \Psi\left(\frac{\mathrm{t}-\mathrm{b}}{\mathrm{a}}\right) \mathrm{dt} \\
& \Psi_{a, b}=\frac{1}{\sqrt{a}} \Psi\left(\frac{t-b}{a}\right) \\
& W(a, b)=\int_{-\infty}^{\infty} x(t) \Psi_{a, b}(t) d t
\end{aligned}
$$

Bu denklemlerde $\mathrm{a}>0, \mathrm{~b} \in \mathrm{R}$ olmak üzere a, ölçekleme parametresini; $b$ dönüşüm parametresini; $\mathrm{x}(\mathrm{t})$, işareti; $\psi$, dalgacık fonksiyonunu (ana dalgacığ 1 ); W(a,b) ise işaretin sürekli dalgacık dönüşümünü belirtir [18].
2.3.1. Ayrık Dalgacık Dönüşümü (ADD) (Discrete Wavelet Transform)

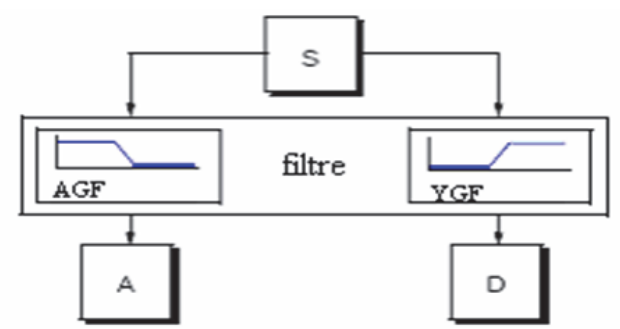

Şekil 1. Dalgacık Analizinin Gösterimi (Wavelet Transform)

Filtre sonucunda oluşan iki ayrı sinyalden A ile gösterilene Yaklaşıklık (Approximation) ve D ile gösterilene de Ayrıntı (Detail) ismi verilir. Yaklaşıklık işaretleri, orijinal işareti temsil eder ve işaretin tanımını verir. Ayrıntılar ise işaretin karakteristiğini yada ayrıntısını içerir [19]. Yaklaşıklıklar; işaretin orijinalini temsil eder ve yüksek ölçek ile elde edilir. Ayrıntılar ise işaretin yüksek frekanslı bileşenleridir. İşaretlere alçak geçiren ve yüksek geçiren filtreler uygulayarak ve ortaya çıkan verileri 2'nin kuvvetleri formunda azaltarak ADD uygulanabilir. $\mathrm{Bu}$ işlem çıkan sonuçlara da uygulanırsa çoklu çözünürlük analizi işarete uygulanmış olur [20].

\section{UYGULAMA (CASE STUDY)}

\subsection{Dalgack Analizinin Uygulanması (Wavelet Decomposition Application)}

Doğal serilerin gürültü içerdikleri, daha önceki bölümlerde de vurgulanmıştı. Verinin kaynağ1 kaotikse, bilgi de arka plandaki sinyal de geniş bantlıdır ve Fourier analizi bu ayırımı yapmak için yeterli değildir. Dalgacık dönüşümü ise, farklı pencereleme fonksiyonları ve asimetrik dalgacıklar kullandığından işareti tam olarak betimleyebilmektedir [21]. Böylece işaret hakkında ayrıntılı bilgiye sahip olunmaktadır.

Doğal bir sistem olan Çoruh havzası Devlet Su İşleri Genel Müdürlüğü'ne ait 2304 numaralı akım gözlem istasyonlarından alınan, günlük periyot ile örneklenmiş, 33 yıllık kayıtlı akım verisidir. Veri kümesinin ihtiva ettiği düşünülen gürültünün, frekans bileşeni bilinmediğinden ve hangi bantta yer alacağ1 kestirilemeyeceğinden dolayı, gürültü azatlımı için dalgacık analizi tercih edilmiştir. Yapılacak ayrıştırma işlemi için 10 seviye seçilmiştir.

\subsection{Uygun Seviyenin Seçimi (Selecting the Appropriate Level)}

Dalgacık analizi, zaman serisi analizi için var olan analiz yöntemlerinin en güçlüleri arasında yer almaktadır. Dalgacık analizi uygulanırken; ana dalgacık seçimi, seviye secimi gibi problemler ortaya çıkmaktadır. 
$\mathrm{Bu}$ çalışmada; literatürde en fazla kullanılan, ortogonal bazlı olma özelliği taşıyarak, ayrıştırma sonrasında işarete geri dönmemize olanak sağlayan Debauchie Ana dalgacığı kullanılmıştır.

Dalgacık analizi sonucunda, uygun seviyenin seçimi için, seçilen seviyedeki yaklaşıklık bileşenin, istenmeyen gürültüden ayrılmış olmasının yanı sıra, gözlenmiş seriyi temsil edebilmesidir. Bunun için serinin içerdiği bilginin bir ölçütü olan entropi kavramı kullanılacaktır. Ayırılacak olan parçanın seviyesinin seçiminde, bilgi taşıma kapasitesi göz önünde bulundurulacaktır. Bilgi kaybının başladığı seviyede ayrıştırma yapılacak ve bilgi içermeyen parça gürültü olarak kabul edilecektir.

\subsubsection{Entropi Kavramı (Entropy Concept)}

Entropi, ölçütünün tanımı; anlamına, türüne, değerine veya diğer herhangi bir sübjektif özelliğine bakılmaksızın, iletişim yaratan sembol, sinyal ya da sayılar dizisinin istatistiksel yapısını analiz eden bilgi (enformasyon) kuramına dayanmaktadır. Burada "bilgi içeriği" terimi, iletişim yaratabilecek sinyal üretme yeteneği olarak tanımlanmaktadır ve bu, çerçevede problem; herhangi bir bilgi kaybına veya tekrarına yol açmadan, yeterli miktarda sinyal göndererek, iletişimin doğru olarak yapılmasıdır. Bilgi kuramının temel prensipleri, iletişim hatlarından sinyal gönderilmesi işlevini stokastik bir süreç olarak ele alan Shannon [22] tarafından geliştirilmiştir.

Bilgi Kuramına göre; Shannon Entropi’si (H) ; Eşitlik (10)'daki gibi hesaplanır.

$H(x)=-\sum_{i=1}^{n}\left(p\left(x_{i}\right)\left(\log _{2}\left(p\left(x_{i}\right)\right)\right)\right.$

$p\left(x_{i}\right), \mathrm{n}$ boyundaki $\mathrm{x}$ değişkeninin, rastgele karakterli olasılık yoğunluk dağılımını ifade etmektedir. Logaritma'da 2 tabanının kullanılmasının sebebi ise, bilgi teorisinin bit ölçütünü kullanmasıdır.

Entropi (H) aynı zamanda bilginin de bir ölçütüdür. Düşük değerli entropilere sahip işaretler düzensizlik az olduğu için daha fazla bilgi taşımaktadır.

\subsubsection{Dalgacık Entropisi (Wavelet Entropy)}

Dalgacık entropisi hesaplamak için; ADD sonucunda elde edilen parçaların enerjilerinin oranlarına bakılmaktadır.

$\mathrm{Bu}$ amaçla, ADD sonucunda elde edilen katsayıların enerjilerini (E), hem zaman $(i)$ hem de frekans $(j)$ skalasında, vektörel olarak hesaplanarak, olasılık dağılımı.

$P_{i j}=\frac{E_{i j}}{E_{i}}$ ve dalgacık entropisi Eşitlik 12 ile hesaplanır.

$W=-\sum_{j=1}^{N} P_{i j} \times \log _{2} P_{i j}$

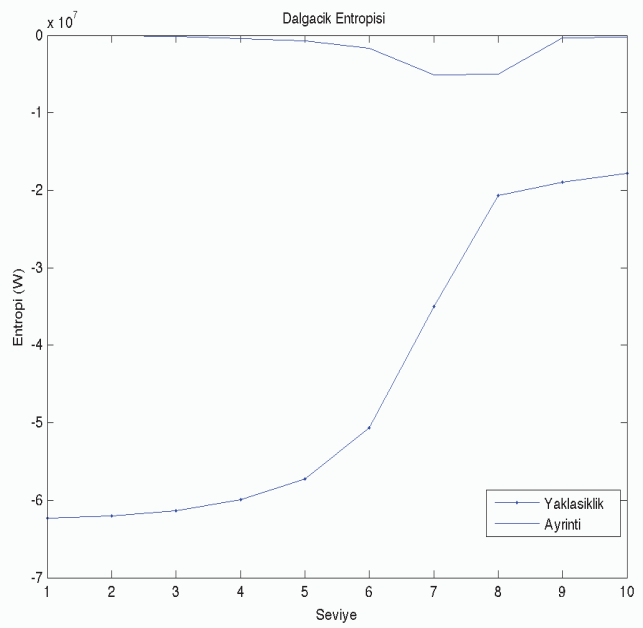

Şekil 2. Entropi Değerleri (Entropy Values)

Entropinin aynı zamanda bilginin bir ölçütü olduğu göz önünde bulundurulacak olursa, entropinin artış1, serideki düzensizliğin artışı ve bilgi kaybını göstermektedir. Gözlenmiş serinin içerdiği istenmeyen gürültü parçasını ayırmak için, seçilecek uygun seviye için kriter taşınan bilgidir. Bu durumda, 5. Seviye ayrıştırma için uygun seviye olarak belirlenmiştir (Şekil 2).

\subsection{Faz Uzayının Yeniden Kurulması (Phase Space} Reconstruction)

Daha önce yapılan araştırmalarda, günlük nehir akımlarının geniş bir aralıkta, deterministik karakter ile gürültülü stokastik karakter arasında değişim gösterdiği sonucuna varılmıştır [1]. Stokastik karakterli olarak nitelendirilen, gürültülü serinin öngörü başarımını düşürdüğü ve gürültüsü giderilmiş serinin ise deterministik karakter göstererek öngörüde daha başarılı sonuçlar verdiği gözlenmiştir. Bunun yanı sıra, gürültünün yeniden kurulan faz uzayında oluşan çekicinin fraktal boyutunu yükselttiği gözlenmiștir. Uygulamanın bu bölümünde hem gözlenmiş hem de dalgacık analizi 5. Seviye sonucunda elde edilmiş yaklaşıklık parçası için (Şekil 3), faz uzayı yeniden kurularak, korelasyon boyutları yöntemi ile faz uzayında oluşan çekici boyutu incelenmiştir.

Faz uzayı yeniden kurulurken, zaman gecikmeli koordinatlar yöntemi kullanılmıștır. Zaman gecikmesi $\mathrm{T}$, ortak bilgi fonksiyonun $\mathrm{I}(\mathrm{t})$ ile hesaplanmıştır. Elde edilmiş ortak bilgi fonksiyonu kullanılarak elde edilmiş zaman gecikmeleri (T) gözlenmiş seri için 65 gün, yaklaşıklık parçası(A5) için 70 gün olarak belirlenmiștir. 

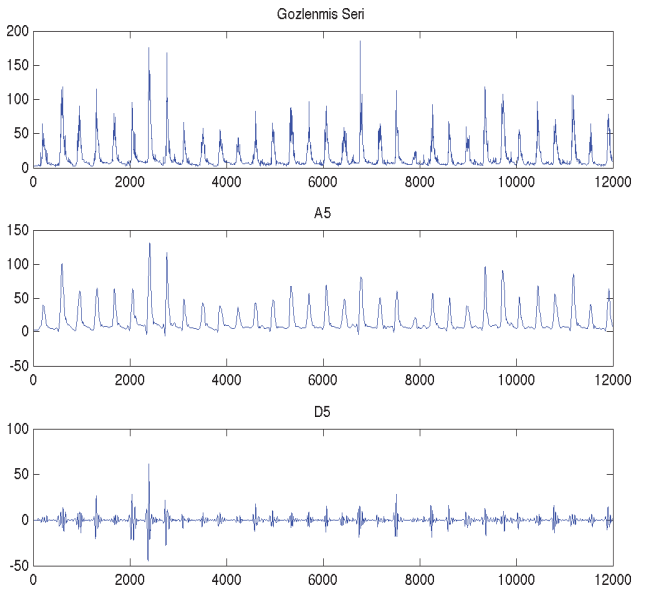

Şekil 3. Gözlenmiş Seri ve 5. seviye Dalgacık Analizi (Wavelet Transformation on the $5^{\text {th }}$ Level of Decomposition)

Elde edilen değerlerden de gözlenebileceği üzere, ayrıştırma sonucunda elde edilen parça (A), serinin orijinal haline göre daha büyük erteleme zamanına sahiptir. $\mathrm{Bu}$ bilgininin gürültüsü giderilmiş parçada daha uzun süre taşınabileceğinin bir göstergesidir. Ortak bilgi fonksiyonu ile belirlenen zaman gecikmesi (T) ile oluşan zaman kopyalarının oluşturduğu çekerin 3 boyutlu uzaydaki $(\mathrm{x}(\mathrm{t}), \mathrm{x}(\mathrm{t}+\mathrm{T}), \mathrm{x}(\mathrm{t}+2 \mathrm{~T}))$ gösterimi, gözlenmiş seri, yaklaşıklık bileşeni (A) için Şekil 4'te gözlenebilmektedir.

\subsection{Gömme Boyutunun Belirlenmesi (Estimating} Embedding Dimension)

Faz uzayının koordinatları, sistemin evrimini tam olarak gösterebilmek için gerekli olan durum değişkenlerinden meydana gelir.

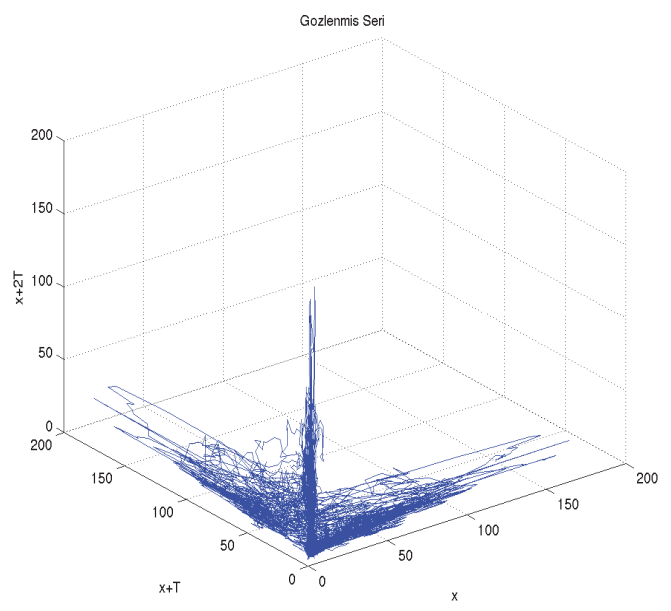

Şekil 4. (a) Çekerler a-Gözlenmiş Seri, b-Yaklaşıklık Bileşeni (A)(Attractors a- Observed Series, b-Approximation Component)

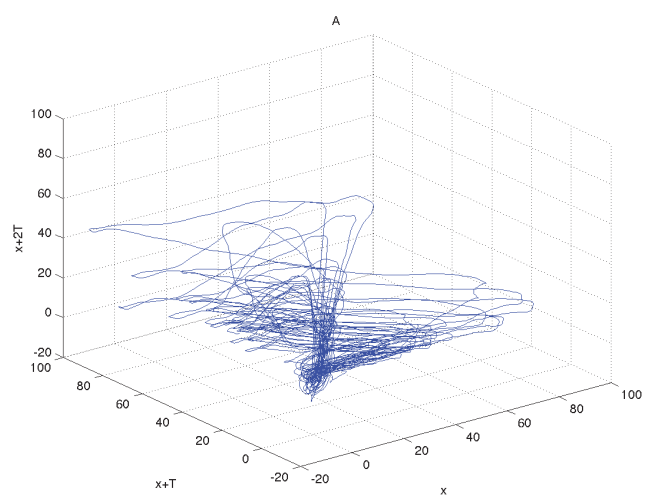

Şekil 4. (b) Çekerler a-Gözlenmiş Seri, b-Yaklaşıklık Bileşeni (A)(Attractors a- Observed Series, b-Approximation Component)

Takens [13] teoremine göre, sistemin gecikmeli kopyaları faz uzayında uygun boyutta gömülürse, davranışını belirleyen yörüngeler daha net gözlenebilir. Sistemin oluşturulan faz uzayında yörüngelerin oluşturduğu çekerin boyutunu belirlemek için, korelasyon boyutları yönteminin kullanılmıştır. Korelasyon boyutları hesaplanırken Hegger vd. [23], tarafından 1999 yılında oluşturulan Time Series Analysis (TISEAN), programı kullanılmıştır. $\mathrm{Bu}$ program literatürde, kaotik analiz için en sık kullanılan programdır. Korelasyon boyutu yönteminden elde edilen sonuçlardan da görüleceği üzere, davranış çift logaritmik eksenin belirli bir noktasında doyuma ulaşmaktadır (Şekil 5). Doğrusal hareket gösteren bu bölgenin eğimi ise, faz uzayında oluşacak çekerin topolojik boyutunu vermektedir [24]. Elde edilen bu sistem (çeker) boyutu eğer fraktal ise bu serinin kaotik davranış gösterdiğinin bir kanıtıdır Eğer bu eğimler, belirli gömülü boyutlarına karşı çizilirse, fraktal boyutta bir doyum gözlenir.

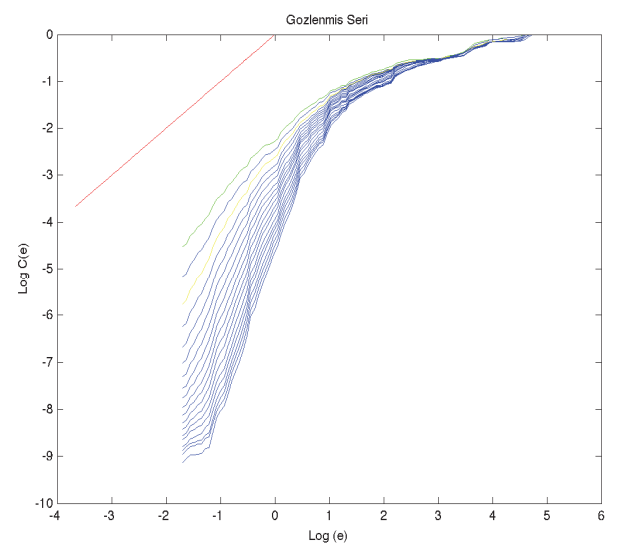

Şekil 5. (a) Gözlenmiş Seri (a) ve Yaklaşıklık bileşeni (A)'na (b) ait Korelasyon Integralleri (Coorelation Integral for a) Obsorved Series b) Approximation Component, Dimension) 


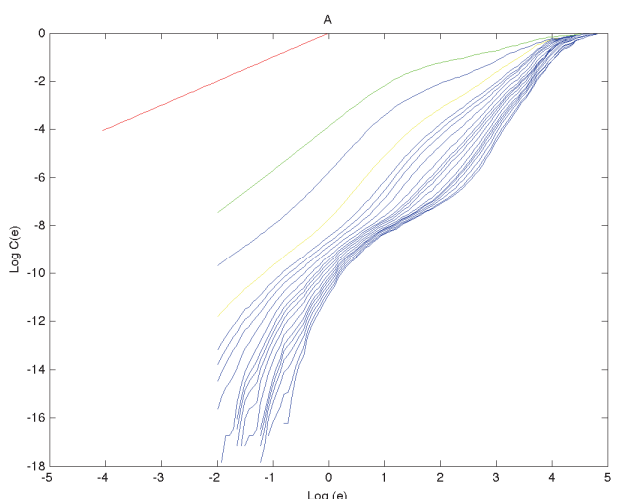

Şekil 5. (b) Gözlenmiş Seri (a) ve Yaklaşıklık bileşeni (A)'na (b) ait Korelasyon Integralleri (Coorelation Integral for a) Obsorved Series b) Approximation Component, Dimension)

$\mathrm{Bu}$ durum belirli gömülü boyutundan sonra, çekerin boyutunun değişmediğinin bir göstergesidir. Doyum noktasına ulaşılan boyut, çekerin rahat gözlenebilmesi için uygun gömülü boyuttur (Şekil 6).

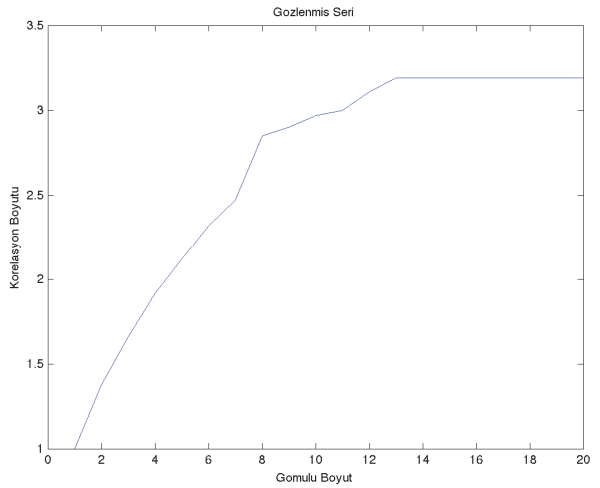

Şekil 6 (a) Gözlenmiş Seri ve Yaklaşıklık Parçası (A) için Gömülü ve Çeker Boyutları (Attractor Dimension a)Obsorved Series b)Approximation Component)

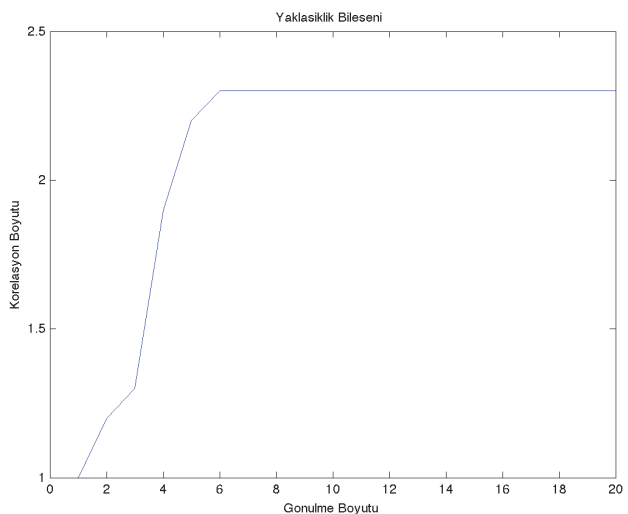

Şekil 6. (b) Gözlenmiş Seri ve Yaklaşıklık Parçası (A) için Gömülü ve Çeker Boyutları (Attractor Dimension a)Obsorved Series b)Approximation Component)

Tablo 1'den de açıkça görüleceği üzere, gürültü bileşenin seri içinde varoluşu, hem gömülü boyutu hem de sistem boyutunun artışına sebep olmaktadır.
Gürültüden ayrılmış parçanın oluşturduğu çeker, gözlenmiş seriye göre çok daha büyük boyuttadır. Yaklaşıklık bileşeninde 2,17 olan çeker boyutu, serinin orjinal halinde 3,17 olarak hesaplanmıştır.

Tablo 1. Gözlenmiş Seri ve Yaklaşıklık Parçası (A) için Gömülü ve Çeker Boyutları

(Embedded and Attractor Dimensions for Obsorved Series and Approximation Component)

\begin{tabular}{|c|c|c|}
\hline & $\begin{array}{l}\text { Gömülü } \\
\text { Boyutu }\end{array}$ & Çeker Boyutu \\
\hline Gözlenmiş Seri & 13 & 3,19 \\
\hline Yaklaşıklık & 6 & 2,17 \\
\hline
\end{tabular}

\subsection{Sistemin Öngörülebilirliği (Predictability of the} System)

\subsubsection{Lokal Öngörü (Local Approximation)}

Doğru kurulmuş bir Faz Uzayı, sistemin içeriğindeki dinamiklerin daha rahat görülebilmesine olanak vermektedir. m-boyutlu uzayda $\mathrm{f}_{\mathrm{T}}$ fonksiyonu yörüngelerle ifade edilebilir (Eşitlik 13).

$Y_{j+T}=f_{T}\left(Y_{j}\right)$

Burada $Y_{j}$ ve $Y_{j+T}$, m boyutlu sistemde, $j$ o anki durumu, $j+T$ ise gelecekteki ( $\mathrm{T}$ zaman sonra ) durumu ifade etmektedir. Amaç, $Y_{j}$ cinsinden $\left(Y_{j+T}\right)$ 'yi ifade edebilecek uygun $f_{T}$ fonksiyonunu bulmaktır. Yerel Yaklaşım Yöntemi, $\mathrm{m}$ - boyutlu uzayda $f_{T}$ fonksiyonunu alt uzaylara (komşulara) bölerek, yeni oluşturulan $f_{T}$ domeninden yaklaşı $\mathrm{k}$ bir $f_{T}$ fonksiyonu elde etmektir. Tek değişkenli bir zaman serisi düşünülecek olursa, uygun gecikme zamanı ve gömülü boyutu belirlenerek bir faz uzayı kolaylıkla kurulabilir. $\mathrm{Bu}$ faz uzayında oluşan yörüngeler sayesinde sistemin içerdiği dinamik hareket rahatça gözlenebilir. Zaman serisinin her bir bileşeni olan $X_{t}$ 'nin $p$ zaman sonra $\left(X_{t+p}\right)$ hareketinin, oluşan yörüngede gözlenebilmesi için $f$ fonksiyonu, Eşitlik 14 'deki gibi ifade edilebilir.

$X_{t+p} \cong F\left(X_{t}\right)$

$X_{t}$ 'nin zamanla değişimi, yörünge üzerindeki komşu noktalar $\left(\mathrm{X}_{\mathrm{T}}, \mathrm{h} 1,2, \ldots, \mathrm{n}\right)$ ile hareketi ile ifade edilebilir. $X_{t+p}$, d dereceli bir polinom ile ifade edilecek olursa (Eşitlik 15,16,17,18),

$X_{t+p} \cong$

$\boldsymbol{f}_{0}+$

$\sum_{k_{i}=0}^{m-1} f_{1 k_{1}} X_{t-k_{1} r}+\sum_{k_{2}=k_{1}}^{m-1} f_{2 k_{1} k_{2}} X_{t-k \tau_{1}} X_{t-k_{2 \tau}}+$

$\sum_{k_{d}=k_{d-1}}^{m-1} f_{d k_{1} k_{2} \ldots \ldots k_{d}} X_{t-k_{1 \tau}} \ldots \ldots X_{t-k_{d} \tau}$

$f^{\substack{k_{2}=k_{1} \\ k_{1}=0}}$

$x \cong \mathrm{A} f$

$x=\left(x_{T_{1+p}}, x_{T_{2+p}}, \ldots \ldots x_{T_{n+p}}\right)$ 
$f=\left(f_{0}, f_{10} f_{11}, \ldots . . f_{1(m-1)}, f_{200}, \ldots \ldots . ., f_{10 d(m-1)(m-1) \ldots(m 1)}\right)(1$

A matrisi oluşturularak polinomum çözümü matrisler cinsinde bulunabilir. Matris çözümü için Eşitlik (21) şartı sağlanmalıdır.

$A=k \times(m+d) !$

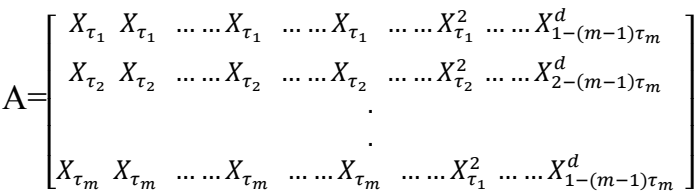

$k \geq \frac{(m+d) !}{m ! d !}$

Porporato ve Ridolfi [5], çalışmalarında belirttiği üzere, polinom 1. Derece olsa bile öngörü yöntemi doğrusal olmayan karakter taşır, çünkü bulunan her $x(t)$ noktası yörünge üzerinde farklı bir komşuyu ifade etmektedir. $\mathrm{Bu}$ durumda, polinom matrisi sürekli değişmek zorundadır [25]. Tek değişkenli zaman serilerinde, çekicinin yörüngesi çok boyutlu bir faz uzayı oluşturularak polinom yaklaşımı ile tahmin edilebilir. Eğer zaman serisinin içerisinde gürültü bileşeni mevcut ise, gürültü bileşeninin sebep olduğu sapmalar öngörü başarısını düşürür [25]. Bu çalışmada, hem gözlenmiş seri hem de yaklaşıklık parçası üzerinde yerel yaklaşım yöntemi uygulanarak, serinin üzerindeki gürültünün öngörülebilirlik üzerindeki etkisi incelenmiştir.

Her iki serinin de aynı uzunlukta olduğu göz önünde bulundurularak; serilerin \%90'lık kısmı öğrenme için kullanılmış, \%10'luk kısmı üzerinde de öngörü yapılmıştır.

Öngörünün performansını belirlemek için korelasyon katsayısı " $\mathrm{R}^{2 "}$ kriteri kullanılmıştır. Öngörünün yapılabilmesi ve uygun boyutun seçilmesi için seriler çeşitli gömülü boyutları için öngörü yapılmış $(m=1$ 10 ), en uygun görülen gömülü boyutu seçilmiştir (Tablo 2). Uygun boyutunun seçiminde ise korelasyon katsayısının ise yükseldiği değere karşılık gelen gömme boyutu seçilmiştir. Boyut her iki seri için de $\mathrm{m}=4$ olarak bulunmuştur.

Öngörü başarımını ifade etmek için, tahmin edilen seriye karşılık, gözlenen serinin grafiği çizilir. Oluşan grafikte iki serinin birbirine göre korelasyonu hesaplanır. Elde edilen korelasyon katsayısı $\left(\mathrm{R}^{2}\right)$, 0,9'da büyük değerler alırsa, tahmin başarılı kabul edilir [26]. Çalışma sonuçlarından elde edilen öngörü performans grafiğinde (Şekil 7) yaklaşıklık bileşeninin başarımın daha yüksek olduğu gözlenmişti
Tablo 2. Çeşitli Gömülü Boyutları için Korelasyon Katsayilar (Correlation Coefficient for different $\mathrm{m}$ )

\begin{tabular}{|c|c|c|}
\hline $\begin{array}{c}\text { GömülüBoyutu } \\
(\mathrm{m})\end{array}$ & $\begin{array}{c}\mathrm{R}^{2} \\
\text { Gözlenmiş } \\
\text { Seri }\end{array}$ & $\begin{array}{c}\mathrm{R}^{2} \\
(\mathrm{~A})\end{array}$ \\
\hline 1 & 0,968 & 0,992 \\
\hline 2 & 0,969 & 0,993 \\
\hline 3 & 0,969 & 0,998 \\
\hline 4 & $\underline{\mathbf{0 , 9 7 6}}$ & $\mathbf{0 , 9 9 9}$ \\
\hline 5 & 0,974 & 0,997 \\
\hline 6 & 0,972 & 0,996 \\
\hline 7 & 0,968 & 0,994 \\
\hline 8 & 0,966 & 0,995 \\
\hline 9 & 0,954 & 0,991 \\
\hline 10 & 0,948 & 0,992 \\
\hline
\end{tabular}

\section{SONUÇLAR ve DEĞERLENDİRME (Results} and Evalution)

Bu çalışmada, Devlet Su İşleri Genel Müdürlüğü’ne ait Çoruh Havzası 2304 numaralı istasyona ait 33 yıllık günlük akım verileri üzerinde kaotik analiz yapılırken, dalgacık analizi yapılarak ayrılan bilgi içermeyen gürültü parçasının faz uzayı oluşumunda ve öngörülebilirlikte etkisi araştırılmıştır.

Çalışma, literatürde vurgulanan doğal serilerin de diğer zaman serileri gibi deterministik ve stokastik parçadan oluştuğu hipotezinin bir uygulaması olarak düşünülebilir. Serinin içindeki deterministik parçanın incelenebilmesi için, üstündeki stokastik örtünün ayrılması gerekmektedir. Bu çalışmada, stokastik parçasının ayrımında dalgacık Analizi kullanılmıştır. Stokastik parçanın, gürültü karakterli, bilgi içermeyen özellik göstereceği varsayılmış ve seri içerisinde bilinen frekanslı bir gürültü belirlenemediğinden dolayı, dalgacık analizi uygulanmıştır. Analizde seviyeyi belirlemek için ise entropi kavramı kullanılmıştır. Serinin dalgacık analizi ile ayrıştırılması esnasında, seviye seçimi için serinin ayrılan parçalarında bilgi kaybının başladığı ve entropinin sıfırdan farklı değer aldığı nokta seçilmiştir. Seçilen seviyedeki ayrıştırmada, serinin orijinal halinin yanı sıra, orijinal hali ile aynı miktarda bilginin korunduğu yaklaşıklık bileşeni üzerinde kaotik analiz yapılmıştır. Faz uzayında oluşan çekerin, sistemin dinamiklerini temsil ettiği göz önünde bulundurulacak olursa; oluşan çekerin boyutunun fraktal yapıda oluşu sistemin kaotik davranışının bir göstergesidir. Uygulamada, dalgacık analizi neticesinde ayrılan iki parçanın da, fraktal çeker boyutlarına sahip olduğu ve kaotik karakter taşıdığı sonucuna varılmıştır. Fakat; serinin orijinal halinin boyutunun, yaklaşıklık bileşenine nazaran daha büyük boyutta oluşu; ayrılan ve bilgi taşımayan parçanın sistemin karakteri üzerinde adeta bir örtün daha büyük olması ayrıştırılan parçanın sistemin dinamiğini gizleyen bir örtü karakteri taşıdığı düşünülebilir. 
Literatürde daha önce yapılan çalışmalarda da, sistemin sahip olduğu gürültünün sistem dinamiğinin belirlenmesini etkilediği ve öngörü başarımını düşürdüğü inceleme altına alınmıştır [25]. Bu çalışmada elde edilen sonuçlar, literatürde bahsi geçen, kaotik analizde sistem gürültüsünün etkisi ile uyum göstermektedir. Uygulamanın son bölümünde, hem gözlenmiş seri hem de yaklaşıklık bileşeni için ayrı ayrı yerel yaklaşım yöntemi kullanılarak öngörü yapılmıştır. deterministik karakterli verilerin daha iyi öngörülebilirliği göz önünde bulundurulursa, uygulamanın bir önceki bölümünün sonucuna uyumlu olarak, serinin içindeki gizli deterministik parçayı gösteren yaklaşıklık bileşeni, gözlenmiş seriye göre yüksek öngörü başarımı göstermiştir. İnsanlığın temel ihtiyacı olan su kaynaklarının etkin kullanımı ve işletilmesi, son dönemlerde etkisi belirgin şekilde hissedilen iklim değişikliği ile önemini git gide arttırmaktadır. Su kaynaklarının doğru analizi ve etkin işletimi için geliştirlen yeni yöntemler, bilimsel alanda gelişim de değerli olmanın yanı sıra, insanlığın sürdürülebilirliği için de elzem bir ihtiyaç haline gelmiştir. Özellikle sulama, içme suyu temini ve enerji üretimi için, nehir akımlarının başarısı yüksek yöntemlerle öngörülmesi git gide daha da önemli hale gelmektedir. Bu çalışmada elde edilen sonuçların, su kaynaklarının öngörülmesi konusunda literatüre katkı sağlayacağı ve bilimsel anlamda da, doğal seriler üzerinde kaotik analiz konusunda örnek teşkil edeceğine inanılmaktadır.

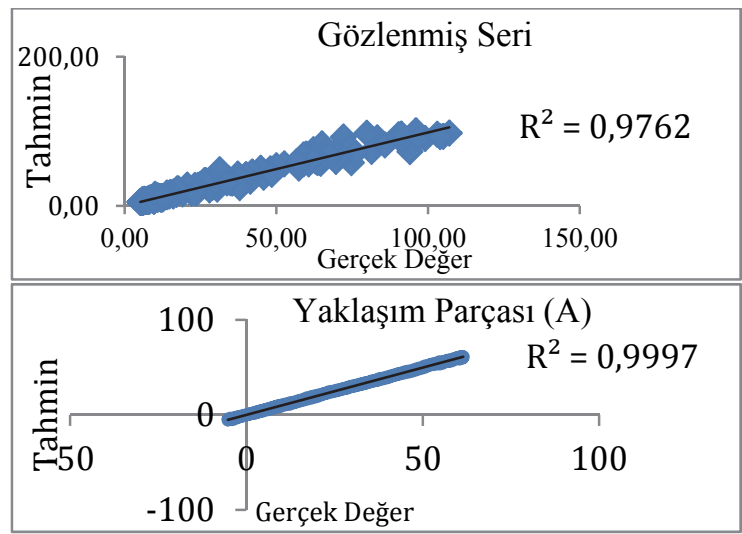

Şekil 7. Öngörü Başarımı (Prediction Performance)

\section{KAYNAKLAR (REFERENCES)}

1. Sivakumar, B., Singh, V.P., "Hydrologic system complexity and nonlinear dynamic concepts for a catchment classification framework" Hydrol. Earth Syst. Sci. Discuss., Cilt 8, 4427-4458, 2011.

2. Kurt E., Kasap R., Karmaşanın Bilimi Kaos, Nobel Yayınları, Ankara, Turkey, 2011.

3. Kantz H., Schriber T., Nonlinear Time Series Analysis, Cambridge University Press, Cambridge, UK, 1997.

4. Rodriguez-Iturbe, I., De Power, B. F., Sharifi, M.B., Georgakakos, P. K. , "Chaos in rainfall",
Water Resour. Res., Cilt 25, No 7, 1667-1675, 1989.

5. Porporato, A., Ridolfi, L., Nonlinear analysis of river flow time sequences, Water Resour. Res., Cilt 33, No 6, 1353-1367, 1997.

6. Jayawardena, A.W., Lai, F, "Analysis and prediction of chaos in rainfall and stream flow time series" J. Hydrol., Cilt 153, 23-52, 1994.

7. Grassberger, P. ve Procaccia, I.,"Measuring the Strangenes of Strange Attractors" Physica D, Cilt 9, 189-208, 1983.

8. Elshorbagy A., Simonovic S. P., Panu U. S., "Noise reduction in chaotic hydrologic time series, facts and doubts", Journal of Hydrology, Cilt 256, 147-165, 2002.

9. Wilks, D.S., "Representing serial correlation of meteorological events and forecasts in dynamic decision-analytic models", Mon. Weather Rev. Cilt 119, 1640-1662, 1991.

10. Koçak, K., Kaotik Davranış Kriteri Olarak Fraktal Boyut Değişimi ve Dinamik Sistemlere Uygulanması, Doktora Tezi, İ.T.Ü, Fen Bilimleri Enst., 1996.

11. Liu, Q., Islam, S., Rodriguez-lturbe, I., Lee, Y.," Phase-space analysis of daily streamflow: characterization and prediction", Adv. Water Resour., Cilt 21, 463-475,1997.

12. Abarbanel, H.D.I., Brown R., Sidorowich J.J. ve Tsimring L.S., "The Analysis of Observed Chaotic Data in Physical Systems", Reviews of Modern Physics, Cilt 65, No 4, 1331-1392, 1993.

13. Urbach, R.M.A., Footprints of Chaos in the Markets: Analyzing Non Linear Time Series in Financial Markets and Other Real Systems, Prentice Hall, UK, 2000.

14. Brown, R., Bryant, P., Abarbanel, H.D.I., "Computing the Lyapunov Spectrum of A Dynamical System from an Observed Time Series", Phys. Rev. A, Cilt 43, No 6, 2787-2806, 1991.

15. Kennel, M., Brown, R., Abarbanel, H.D.I., "Determining embedding dimension for phasespace reconstruction using a geometrical construction”., Phys. Rev. A Cilt 45, 3403-3411, 1992.

16. Yilmaz, D., ve Güler, N. "Kaotik Zaman Serisinin Analizi Üzerine Bir Araştırma", Journal of The Faculty of Engineering and Architecture of Gazi University, Cilt 21, No 4, 759-779, 2006.

17. Ayaz, E., Dalgacıklar ve Elektrik Mühendisliği'ndeki Uygulamaları, Y.Lisans Tezi, İ.T.Ü., Fen Bilimleri Enstitüsü, 1997.

18. Mallat S,G.,"A Theory for Multiresolution Signal Decomposition: The Wavelet Representation", IEEE Transactions on Pattern Analysis and Machine Intelligence, Cilt 2 No 7, 674-693, 1989.

19. Misiti M., Misiti, Y., Oppenheim, G., Poggi, J., User Guide Wavelet Toolbox For Use with MATLAB, Mathworks, Matick(MA), USA,2004

20. Bae, H., Kim, Y,T., Lee, S,H., Kim, S., Lee M,H., "Fault Diagnostic of Induction Motors for 
Equipment Reliability and Health Maintenance based upon Fourier and Wavelet Analysis", Artif Life Robotics , Cilt 9, 112-116, 2005.

21. Sang Y. F., Wanf D., Wu J.,C., Zhu Q. P., Wang L., "Wavelet-Based Analysis on the Complexity of Hydrologic Series Data under Multi-Temporal Scales", Entropy, Cilt 13, 195-210, 2011.

22. Shannon, C.E. ve Weaver, W.,The Mathematical Theory of Communication, Urbana, The University of Illinois Press, Illinois, USA, 1949.

23. Hegger, R., Kantz, H., Schreiber, T., "Practical implementation of nonlinear time series methods: the TISEAN package", Chaos , Cilt 9, 413-435,
1999.

24. Koçak K., Şen Z., "Use of Correlation Dimension Function in Dynamical Systems" Proceedings of The 12th IEEE, International Syposium on Intelligent Control, 16-18, İstanbul, Turkey, 1997.

25. Itoh, K., "A method for predicting chaotic timeseries with outliers", Electron. Commun. in Japan, Cilt 78, No 5, 44-53, 1995.

26. Khatibi R., Sivakumar B., Ghorbani M. A, Kisi O., Kocak K.,Zadeh D. F., "Investigating chaos in river stage and discharge time series", Journal of Hydrology, Cilt 414 , 108-117, 2011. 